\title{
Smart Home: Power Electric Monitoring and Control in Indonesia
}

\author{
https://doi.org/10.3991/ijim.v13i03.10070
}

\author{
Novian Adi Prasetyo( $\left.{ }^{(}\right)$, Andhika Galuh Prabawati, Suyoto \\ Universitas Atma Jaya Yogyakarta, Yogyakarta, Indonesia \\ novian66@gmail.com
}

\begin{abstract}
The development of the Internet of Things Industry in Indonesia is increasing rapidly from year to year. One of the uses in this industry is being able to carry out monitoring, control, and analysis. The smart home is one of the applications of IoT that is used in households to make it easier for humans to monitor and control all devices at home. Most homes in Indonesia have various commonly used resources; these are water, electricity, and gas. These resources will run out quickly if humans cannot use them properly. Therefore we need to monitor and control the resources we have at home. One of the resources that will be monitored and controlled in this study is electricity resources because it is more widely used in every corner of the house and almost all household devices use these electricity resources.

This research proposes a way to do electricity use effectiveness with monitoring and power control using cloud-based IoT. The proposal discussed in the paper is expected to have other benefits besides saving electricity resources, but it is also expected to reduce the cost of energy use at home.
\end{abstract}

Keywords - Monitoring and controlling, power electric system, smart home, IoT

\section{Introduction}

Internet of Things (IoT) is a fast-growing topic because the concept of IoT can potentially affect the way we live, but it also affects humans at work. IoT provides a powerful tool not only connected with wireless communication devices but wireless sensors for utilities needed in homes are better for managing energy use [1].

Technology that is growing rapidly makes a role in building dream homes to increase the comfort and safety of residents. Home automation systems are currently very popular and widely used by many people. Human needs for electricity are also very high, almost all household appliances use electricity. Many people cannot control electricity usage in their own homes. In addition, the use of electric power cannot be seen in detail but can only be seen as a whole when paying electricity bills. Another thing that might happen is an electric leak that is unknown to the user.

Smart House can be one solution to the problems described above. Using Smart home, we can also monitor household appliances remotely [2]. Smart home networks 
can be integrated to fulfill the functions needed in homes and buildings[3]. But smart homes are not enough to make users aware of the environment. In addition it is one of the major challenges that appear in the smart home system based IoT is security issues [4]. Demand to monitor environmental factors almost in all research institutes, industries and even for domestic purpose [5]. Energy efficiency is a key to being able to control all devices at home that use electricity. This research will try to design power savings with IoT control on smart homes. Devices to be controlled such as monitoring electric power on all home devices, controlling lights, TV, air conditioning, dispensers, and fan.

The design of electric power control that has been made, in the future can be implemented by utilizing existing smartphone applications such as telegram and other social media to make it easier for users to access and control all their home devices. The control can be done by making use of smart phones we have, using a Wi-fi signal [6]. Energy control can also be used to control room temperature when occupants of a house enter/leave home[1]. Besides that smart home also needs to be considered because it can improve the quality of human life [7]. Evaluation of datasets obtained through real life is also very interesting to discuss more deeply, this has been proven by other researchers [8]. The application of smart home will certainly have an impact on the behavior of residents and new perceptions [9]. This has been proven by other studies that prove that some people who have implemented this IoT-based smart home have their own motivations that need to be explored more deeply [10]. The results obtained from the existing smart home design implications can encourage future development [14].

\section{Related Work}

Smart Home can be interpreted as a residence that is equipped with the sophistication of information technology that can interact to respond to the needs of residents of the house by means of automating the device, comfort, security, savings. In conducting its operations, smart home needs to be assisted by computer devices and smartphone devices that we have [11]. Smart home designs can also utilize cloud platforms on household appliances [12]. The development of Smart home also needs to be learned about the habits of existing house occupants [13]. Smart home also needs to be seen in terms of security and privacy risk, previous research revealed that the risks found include risk with software and human behavior [10]. Smart homes will become one of the priority areas of strategic energy planning and national policy [14]. Monitoring can be accessed through the web or smartphone that we have. One of the uses of smartphone applications that can be connected with IoT devices is telegram [7]. Monitoring on a smart home can also be developed by creating a real-time schedule for home energy management [15].

IoT is a new concept that provides a series of services for the next wave of technological innovation [16]. The application of IoT has been widely used in various fields, one of which is health. In the world of IoT health combined with sensor devices, according to other studies, monitoring in the field of health based on distance can use 
sensors to send data into software machines [17]. Data that has been collected from these sensors will be sent to the web server to be able to use web-based monitoring [18]. Wireless sensors are the main component, these devices affect the performance and accuracy of the network [19].

\section{Purpose Method}

This research will create a smart home design with the architecture described in Figure 1.

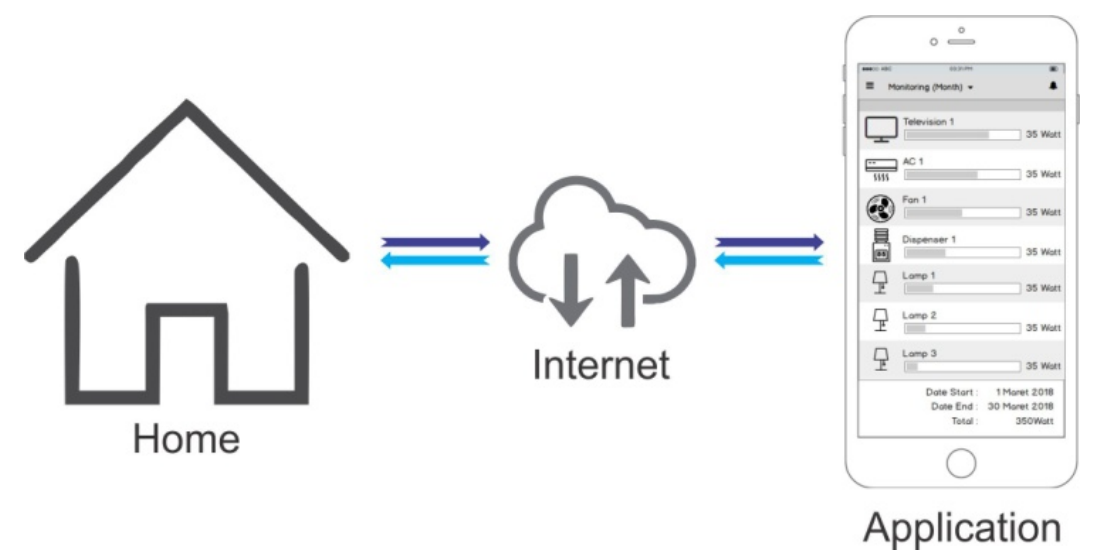

Fig. 1. System Architecture

In Figure 1 explains how the application can monitor and control the home via the internet, on each electronic device an electric current sensor will be installed to read the amount of electric current used by the device, then the data is sent via the internet and stored on the server so that the application can access the data, based on these data the application will process and display the results through notifications for power saving warnings. In Figure 1, there is 2-way communication, which shows that the application not only monitors the home but also can control electricity usage remotely.

\subsection{Power save mode}

Power saving mode is one of the methods used in this study in order to reduce excessive electricity usage based on the results of monitoring, this mode can be controlled manually on each household device or controlled through notification when the electricity usage has or will be over the limit, the working mode of power saving mode is using a PIR sensor and LDR sensor to monitor the state of the house, then the sensor data will be used by a microcontroller to turn off or turn on household devices via a relay automatically when the power saving mode is activated. 


\section{$4 \quad$ Results and Discussion}

\subsection{Smart home design}

In this study, the design of the smart home on the side of the house was built using a set of microcontroller tools and sensors needed. In Table 1 will explain the details of the needs of the devices that will be used as the basis for the construction of a smart home.

Table 1. Microcontroller and Sensor Devices

\begin{tabular}{|c|l|}
\hline No & \\
\hline 1 & Microcontroller \\
\hline 2 & Internet Module \\
\hline 3 & AC Voltmeter \\
\hline 4 & Relay \\
\hline 5 & LDR Sensor \\
\hline 6 & PIR Motion Sensor \\
\hline
\end{tabular}

The microcontroller is the main device that will be used in this study, which is a chip that functions as an electronic circuit controller. In the study [20][21] using the Arduino microcontroller in his research because it is an open source device so the costs used during implementation are quite cheap, in the study [22] they used the Raspberry Pi model B to build a medical treatment project at home, they also used the official Raspberry Pi operating system Raspbian, in this study [23] they use STM32F103 microcontroller for controlling smart home on a LAN network by utilizing wireless sensor network, According to this study [24] BeagleBone is a microcontroller that has high speed proccessing, and has a lot of input and output, but has a high cost. The internet module is a device used for communication between microcontrollers and servers on the internet, in the study [25] of welfare control and comfort in the room for aging population using ESP8266 and combining Arduino for processing and transmitting data to allow data to be accessed through web and via mobile applications in real time. AC Voltmeter is used to calculate the passing current so that power usage can be monitored properly. The relay is used as a circuit breaker that is carried out automatically through a microcontroller. LDR sensors are used to detect day and night through captured light and PIR motion sensors are used to detect the presence of people in the house.

Figure 2 shows the IoT architecture design that will be applied to the house, in that design uses examples of some common devices in Indonesia.

Figure 2 (a) is a part of the microcontroller in which wifi has been embedded to communicate with the server

Figure 2 (b) is a relay circuit that will function to disconnect electricity from the device, this relay will work in 2 conditions, the first condition is working according to the remote done by the user through the application, the second condition works automatically when the power saving mode is activated 
Image 2 (c) is a voltmeter component installed in each channel of the socket, the purpose is to calculate the power used in each socket. Figure 2 (d) is part of a household device that is connected to a socket that has a voltmeter attached, this household device that will be controlled by electricity. Figure 2 (e) is a group of sensors that will be used as automatic relay control in Figure 2 (b), the sensor will only work if the power saving mode is activated, then the output of the sensor will rule the microcontroller to disconnect or connect the relay.

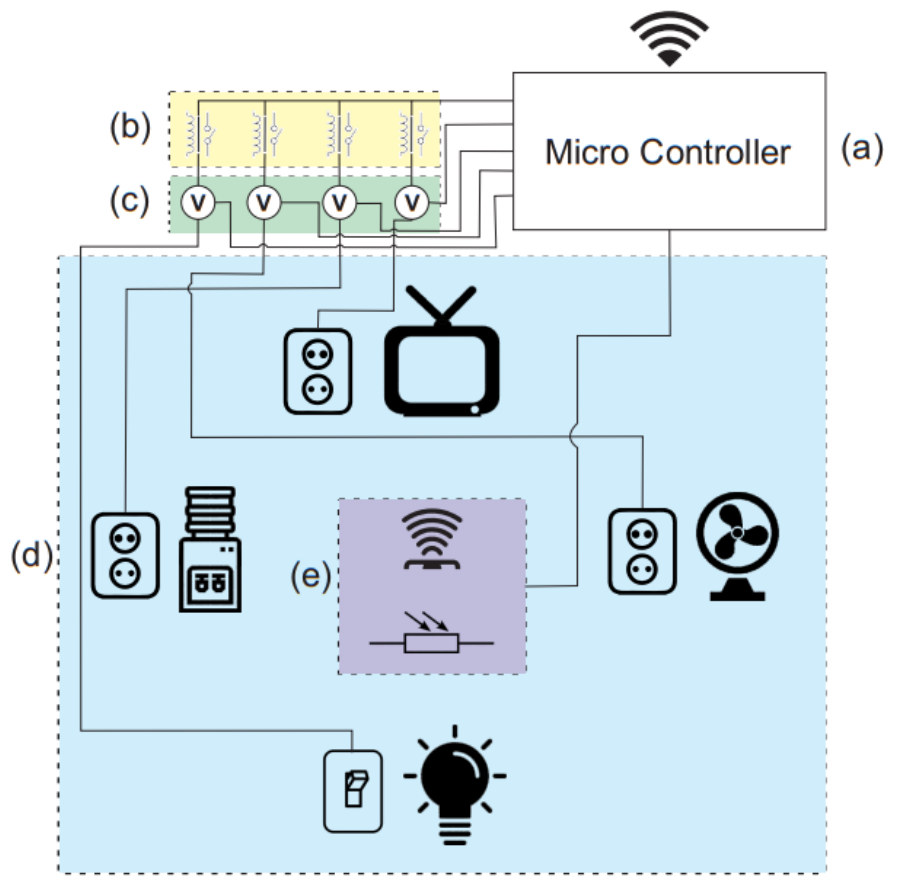

Fig. 2. Smart Home Design

\subsection{Design of smart home applications}

The mobile application is built to control and monitor household devices that have been connected to the microcontroller, each $\mathrm{I} / \mathrm{O}$ pin number on the microcontroller is connected to the server so that on mobile devices only need to do pin number matching so that control and monitoring can be done with household devices right. In the application section, there are features that can be used to monitor the use of electric power and control electrical power, in Figure 3 will display the design requirements of the application.

Figure 3 (a) displays the main dashboard page of the application, on this page is displayed the total electricity usage for one month and a pie chart that contains data on the amount of electricity that has been used (marked with thick color) and the remaining electrical unused (marked with thin colors). Under the pie chart, there is data 
that displays the total electricity usage for one day. At the bottom, there is a button to access important menus in the application. In figure 3 (b) displaying pages for adding household devices, household devices that can be added are devices that have been connected to a microcontroller and are connected to the server, based on the data server, then household devices can be connected to the smart home application using pin number I / O on a microcontroller.

In figure 3 (c) displays a page for controlling household devices, the control is to turn on and turn off household devices using the application, besides that there is a feature to edit and delete household devices that have been stored in the application. In Figure 3 (d) displaying a list of household devices connected with smart home applications, each household device can be seen for a total of one month's power usage, when the household device consumes too much electricity then the user can activate the save mode electricity by touching on the household device to be controlled, after that a popup will appear as shown in Figure $3(\mathrm{~g})$, the popup displays details of daily and monthly electrical power usage and a button to enable or disable the selected household device. In Figure 3 (e) displays the settings page to set the application to bring up a reminder in the form of notification as seen in Figure 3 (f), if the notification setting is activated the system will display a notification according to the electricity usage limit within one month and the percentage usage limit electricity. the electricity usage limit can be filled according to household needs, the goal is that he system is able to remind when the electricity usage is almost over the limit. By default the system will send a notification if the limit has been used above $80 \%$, the percentage value can be set according to the user's wishes.

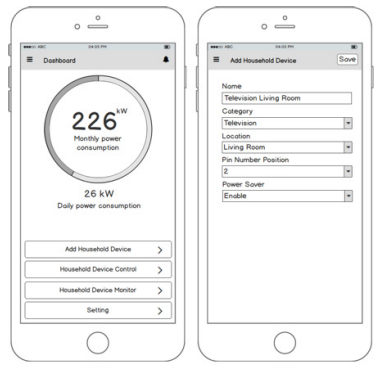

(A)

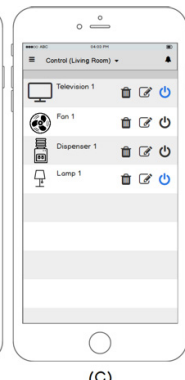

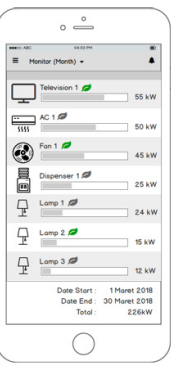

(D)

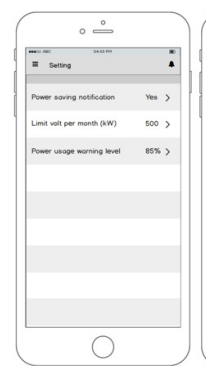

(E)

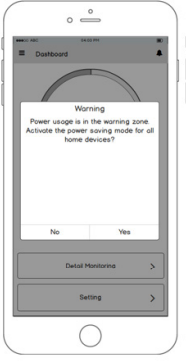

(F)

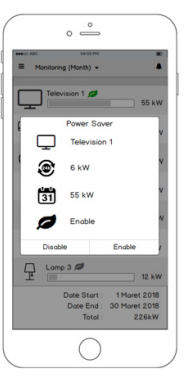

(G)

Fig. 1. Smart Home Mobile Application 


\subsection{Smart home application flowchart}

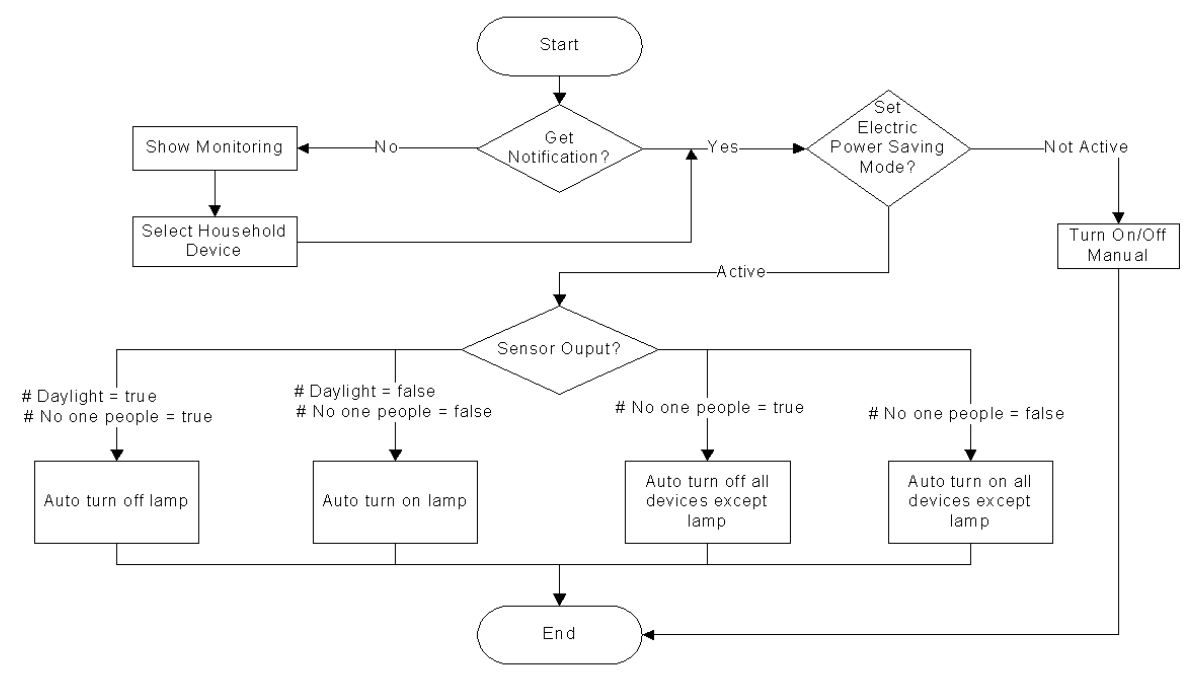

Fig. 3. Flow Smart Home Application

In this study, the application will be designed using a mobile application so that users can access from mobile devices. In Figure 4 describes the process flow of the smart home application in monitoring and controlling.

When the application is opened the first feature displayed is the power usage monitoring feature that has been used during the current month. In silent conditions the application still works and monitors power usage, if the power usage is approaching the limit automatically the system will give a notification to activate the electric power saving mode with the aim of reducing the level of usage of electric power. When the power saving mode is active, the output of the sensor will be noticed by the microcontroller, the infrared sensor will be noticed by the microcontroller to detect the presence of occupants in a space, the LDR sensor will be noticed by the microcontroller to detect daylight. If the room is uninhabited during the day, the microcontroller will order the relay to disconnect the power of the lamp so that the lamp device will turn off and come back to life when the occupants come back into the room during the day. If the room is not inhabited, the microcontroller will order the relay to disconnect all household devices except the lamp so that all household devices except the lamp will turn off and turn on again when the occupants reenter the room.

\section{Conclusion}

The steps and designs that have been made, are expected to be a new proposal, especially for the people of Indonesia in order to be able to control electric power using sophisticated equipment that can be controlled with a smartphone. This control can 
affect the cost of electricity bills that must be paid every month. In the future, the application can be utilize GPS as a technique of tracking the position of the homeowner with smart home, so that the smart home can be detected when the homeowner will go home.

\section{References}

[1] L. Salman, S. Salman, S. Jahangirian, M. Abraham, F. German, C. Blair, and P. Krenz, "Energy efficient IoT-based smart home," 2016 IEEE 3rd World Forum Internet Things, WF-IoT 2016, pp. 526-529, 2017.

[2] W. Gao, W. Yang, K. Xie, and G. Xie, "Design of Smart Home Remote Monitoring System Based on Embedded System,” Inf. Technol. J., vol. 12, no. 18, pp. 4468-4471, 2013. https://doi.org/10.3923/itj.2013.4468.4471

[3] V. Asghari and M. Cheriet, "Energy and connectivity aware resource optimization of nodes traffic distribution in smart home networks," Futur. Gener. Comput. Syst., vol. 88, pp. 559-570, 2018. https://doi.org/10.1016/j.future.2018.05.076

[4] T. Adiono, B. Tandiawan, and S. Fuada, "Device protocol design for security on internet of things based smart home," Int. J. Online Eng., vol. 14, no. 7, pp. 161-170, 2018. https://doi.org/10.3991/ijoe.v14i07.7306

[5] J. P. Sipani, R. H. Patel, T. Upadhyahya, and A. Desai, "Wireless Sensor Network for Monitoring \&amp; Control of Environmental Factors using Arduino," Int. J. Interact. Mob. Technol., vol. 12, no. 2, p. 15, 2018. https://doi.org/10.3991/ijim.v12i2.7415

[6] Y. E. Dari, S. S. Suyoto, and P. P. Pranowo, "CAPTURE: A Mobile Based Indoor Positioning System using Wireless Indoor Positioning System,” Int. J. Interact. Mob. Technol., vol. 12, no. 1, p. 61, 2018.

[7] M. Chen, J. Yang, X. Zhu, X. Wang, M. Liu, and J. Song, "Smart Home 2.0: Innovative Smart Home System Powered by Botanical IoT and Emotion Detection," Mob. Networks Appl., vol. 22, no. 6, pp. 1159-1169, 2017. https://doi.org/10.1007/s11036-017-0866-1

[8] C. Lago, P., Roncancio, C., \& Jiménez-Guarín, "Learning and managing context enriched behavior patterns in smart homes," Futur. Gener. Comput. Syst., vol. 91, pp. 191-205, 2019. https://doi.org/10.1016/j.future.2018.09.004

[9] C. M. Bhati, A., Hansen, M., \& Chan, "Energy conservation through smart homes in a smart city: A lesson for Sin-gapore households," . Energy Policy, vol. 104, pp. 114-126, 2017. https://doi.org/10.1016/j.enpol.2017.01.032

[10] M. Alaa, A. A. Zaidan, B. B. Zaidan, M. Talal, and M. L. M. Kiah, "A review of smart home applications based on Internet of Things,” J. Netw. Comput. Appl., vol. 97, pp. 4865, 2017. https://doi.org/10.1016/j.jnca.2017.08.017

[11] [11] D. Raposo, S. Lucia, F. Boavida, A. Rodigues, and J. Silva, "Industrial IoT Monitoring: Technologies and Architecture Proposal," Sensors (Switzerland), vol. 18.

[12] F. Zambonelli, Franco \& de Meuter, Wolfgang \& Kanhere, Salil \& Loke, Seng \& Salim, "Smart cities: Intelligent environments and dumb people? Panel summary," 2016.

[13] S. Feng, P. Setoodeh, and S. Haykin, "Smart home-CIoT paper," IEEE Commun. Mag., vol. 55, no. 2, pp. 34-39, 2017. https://doi.org/10.1109/MCOM.2017.1600682CM

[14] C. Wilson, T. Hargreaves, and R. Hauxwell-Baldwin, "Benefits and risks of smart home technologies,” Energy Policy, vol. 103, no. September 2016, pp. 72-83, 2017.

[15] S. Li, J. Yang, W. Z. Song, and A. Chen, "A Real-Time Electricity Scheduling for Residential Home Energy Management,” IEEE Internet Things J., vol. 4662, no. c, pp. 1-1, 2018. 
[16] A. Čolaković and M. Hadžialić, "Internet of Things (IoT): A review of enabling technologies, challenges, and open research issues," Comput. Networks, vol. 144, pp. 17-39, 2018. https://doi.org/10.1016/j.comnet.2018.07.017

[17] R. K. Pathinarupothi, P. Durga, and E. S. Rangan, "IoT Based Smart Edge for Global Health: Remote Monitoring with Severity Detection and Alerts Transmission," IEEE Internet Things J., vol. PP, no. c, p. 1, 2018.

[18] M. Khan, B. N. Silva, and K. Han, "A web of things-based emerging sensor network architecture for smart control systems," Sensors (Switzerland), vol. 17, no. 2, 2017.

[19] F. Karray, M. W. Jmal, A. Garcia-Ortiz, M. Abid, and A. M. Obeid, "A comprehensive survey on wireless sensor node hardware platforms," Comput. Networks, vol. 144, pp. 89110, 2018. https://doi.org/10.1016/j.comnet.2018.05.010

[20] B. Ali, A. S., Zanzinger, Z., Debose, D., \& Stephens, "Open Source Building Science Sensors (OSBSS): A low-cost Arduino-based platform for long-term indoor environmental data collection," Build. Environ. vol. 100, pp. 114-126, 2016. https://doi.org/10.1 016/j.buildenv.2016.02.010

[21] M. Alotaibi, M. Albalawi, and L. Alwakeel, "A Smart Mobile Pregnancy Management and Awareness System for Saudi Arabia,” Int. J. Interact. Mob. Technol., pp. 112-125, 2018.

[22] L. Y. Mano, B. S. Faiçal, L. H. V. Nakamura, P. H. Gomes, G. L. Libralon, R. I. Meneguete, G. P. R. Filho, G. T. Giancristofaro, G. Pessin, B. Krishnamachari, and J. Ueyama, "Exploiting IoT technologies for enhancing Health Smart Homes through patient identification and emotion recognition," Comput. Commun., vol. 89-90, pp. 178-190, 2016. https://doi.org/10.1016/j.comcom.2016.03.010

[23] C. Liu, B. Li, and G. Shi, "Design of electronic remote control system based on wireless sensor," Int. J. Online Eng., vol. 13, no. 5, pp. 146-159, 2017. https://doi.org/1 0.3991/ijoe.v13i05.7057

[24] M. El Beqqal and M. Azizi, "Taxonomy on IoT Technologies for Designing Smart Systems Background on IoT technologies and major issues," Int. J. Interact. Mob. Technol., vol. Vol 12, No, pp. 182-192, 2018.

[25] R. P. G. Marques, "An indoor monitoring system for ambient assisted living based on internet of things architecture," Int. J. Environ. Res. Public Heal., vol. 13.no.11, 2016.

\section{$7 \quad$ Authors}

Novian Adi Prasetyo is a Magister Teknik Informatika Student at Universitas Atma Jaya Yogyakarta, Yogyakarta, Indonesia. He is a scholar of the Stikom Yos Sudarso Purwokerto. His research interests are the mobile app, web programming, and machine learning.

Andhika Galuh Prabawati is a Magister Teknik Informatika Student at Universitas Atma Jaya Yogyakarta, Yogyakarta, Indonesia. His research interests are the database, data warehouse, and mobile app user experience.

Suyoto is Professor in Department of Informatics Engineering at Universitas Atma Jaya Yogyakarta, Indonesia. He has more than seventeen years of teaching experience. He received his Ph.D. in 2000 from the National University of Malaysia, Malaysia. His research interests are multimedia, computer graphics, visualization, mobile application, and artificial intelligence.

Article submitted 2019-01-01. Resubmitted 2019-02-19. Final acceptance 2019-02-23. Final version published as submitted by the authors. 